\title{
Bile pigments in pulmonary and vascular disease
}

\author{
Stefan W. Ryter ${ }^{1,2 *}$ \\ Division of Pulmonary and Critical Care Medicine, Department of Medicine, Brigham and Women's Hospital, Boston, MA, USA \\ ${ }^{2}$ Adjunct Scientist, Lovelace Respiratory Research Institute, Albuquerque, NM, USA
}

\section{Edited by:}

Mahin D. Maines, University of

Rochester School of Medicine, USA

Reviewed by:

William Durante, University of

Missouri, USA

Leo Otterbein, Harvard Medical

School, USA

${ }^{*}$ Correspondence:

Stefan W. Ryter, Division of Pulmonary and Critical Care Medicine, Department of Medicine, Brigham and Women's Hospital, 75 Francis

Street, Boston, MA 02115, USA.

e-mail:sryter@partners.org
The bile pigments, biliverdin, and bilirubin, are endogenously derived substances generated during enzymatic heme degradation. These compounds have been shown to act as chemical antioxidants in vitro. Bilirubin formed in tissues circulates in the serum, prior to undergoing hepatic conjugation and biliary excretion. The excess production of bilirubin has been associated with neurotoxicity, in particular to the newborn. Nevertheless, clinical evidence suggests that mild states of hyperbilirubinemia may be beneficial in protecting against cardiovascular disease in adults. Pharmacological application of either bilirubin and/or its biological precursor biliverdin, can provide therapeutic benefit in several animal models of cardiovascular and pulmonary disease. Furthermore, biliverdin and bilirubin can confer protection against ischemia/reperfusion injury and graft rejection secondary to organ transplantation in animal models. Several possible mechanisms for these effects have been proposed, including direct antioxidant and scavenging effects, and modulation of signaling pathways regulating inflammation, apoptosis, cell proliferation, and immune responses. The practicality and therapeutic-effectiveness of bile pigment application to humans remains unclear.

Keywords: antioxidant, biliverdin, bilirubin, cardiovascular disease, pulmonary disease

\section{INTRODUCTION}

Natural antioxidants constitute an important part of host defenses against environmental exposure to noxious agents (Davies, 1995). Pro-oxidant states arise when reactive oxygen species (ROS) formed during metabolism exceed cellular antioxidant capacity (Davies, 1995). Although ROS act as mediators of cellular homeostatic regulation and signaling (Forman et al., 2010), excessive ROS production may contribute to the pathogenesis of human diseases, including cancer, and cardiovascular diseases (CVD; Dröge, 2002; Valko et al., 2006; Sugamura and Keaney, 2011). Cells contain water and lipid soluble chemicals and antioxidant enzymes that function to limit harmful oxidative reactions and preserve tissue homeostasis (Halliwell and Gutteridge, 1999; Davies, 2000). Additionally, many dietary substances can be absorbed and serve as systemic antioxidants (Kaliora et al., 2006; García-Lafuente et al., 2009). Thus, much research has been directed toward the exploitation of naturally occurring antioxidant compounds as therapeutics in the prevention or treatment of human disease (Kaliora et al., 2006; García-Lafuente et al., 2009; Sugamura and Keaney, 2011).

The bile pigments biliverdin (BV) and bilirubin (BR) originate as the products of heme degradation (Roy-Chowdhury et al., 2008; Figure 1). These pigments have been regarded by the medical community as waste products of metabolism (Vitek and Ostrow, 2009). However, BV/BR exhibit antioxidant properties in model systems (Stocker et al., 1987a). Circulating BR acts as a potent serum antioxidant, and serves as a natural anti-atherogenic factor (Stocker et al., 1987b). Retrospective and prospective clinical studies indicate that mildly elevated levels of BR (mild hyperbilirubinemia) are associated with reduced CVD risk (Franchini et al., 2010). Beneficial effects of pharmacological BR/BV have been described in pre-clinical models of tissue injury and disease, including organ transplantation, lung disease, and CVD (Ollinger et al., 2007; Ryter et al., 2007). These effects involve antioxidant, anti-inflammatory, anti-apoptotic, and anti-proliferative mechanisms (Ollinger et al., 2007; Ryter et al., 2007). This review discusses the therapeutic application of the BR/BV in disease, as well as clinical data on the role of endogenous BR as an inverse risk factor for CVD.

\section{ORIGIN AND METABOLIC FATE OF BILIRUBIN}

Bilirubin formed in vivo originates from hemoglobin turnover ( $\sim 80 \%)$ during the degradation of erythrocytes by reticuloendothelial macrophages. The remainder of BR formation results from hemoprotein turnover in systemic tissues. Biliverdin-IX $\alpha$ $(\mathrm{BV}-\mathrm{IX} \alpha)$, the precursor to $\mathrm{BR}$, is a water soluble pigment that originates during heme degradation catalyzed by heme oxygenase activity (HO; E.C. 1:14:99:3), represented by constitutive (HO-2) and inducible (HO-1) isozymes (Tenhunen et al., 1969; Maines, 1997).

Heme oxygenase activity, the rate-limiting step in heme degradation, requires three moles $\mathrm{O}_{2}$ per heme oxidized, and electrons from NADPH cytochrome-p450 reductase (Yoshida and Kikuchi, 1974; Noguchi et al., 1979; Yoshida et al., 1980). Each mole of BV-IX $\alpha$ formed yields one mole each of carbon monoxide (CO), derived from the heme $\alpha$-methene carbon, and ferrous iron (Tenhunen et al., 1969). BV-IX $\alpha$ is reduced to bilirubin-IX $\alpha$ (BR-IX $\alpha$ ), a lipid soluble pigment, by NADH/NADPH-dependent biliverdin reductase (BVR; E.C. 1.3.1.24; Tenhunen et al., 1970).

Bilirubin follows a sequence of biological transformation and elimination steps (Figure 2). BR formed in situ passes to the serum where it circulates in a complex with serum albumin (RoyChowdhury et al., 2008; Vitek and Ostrow, 2009). A fraction 

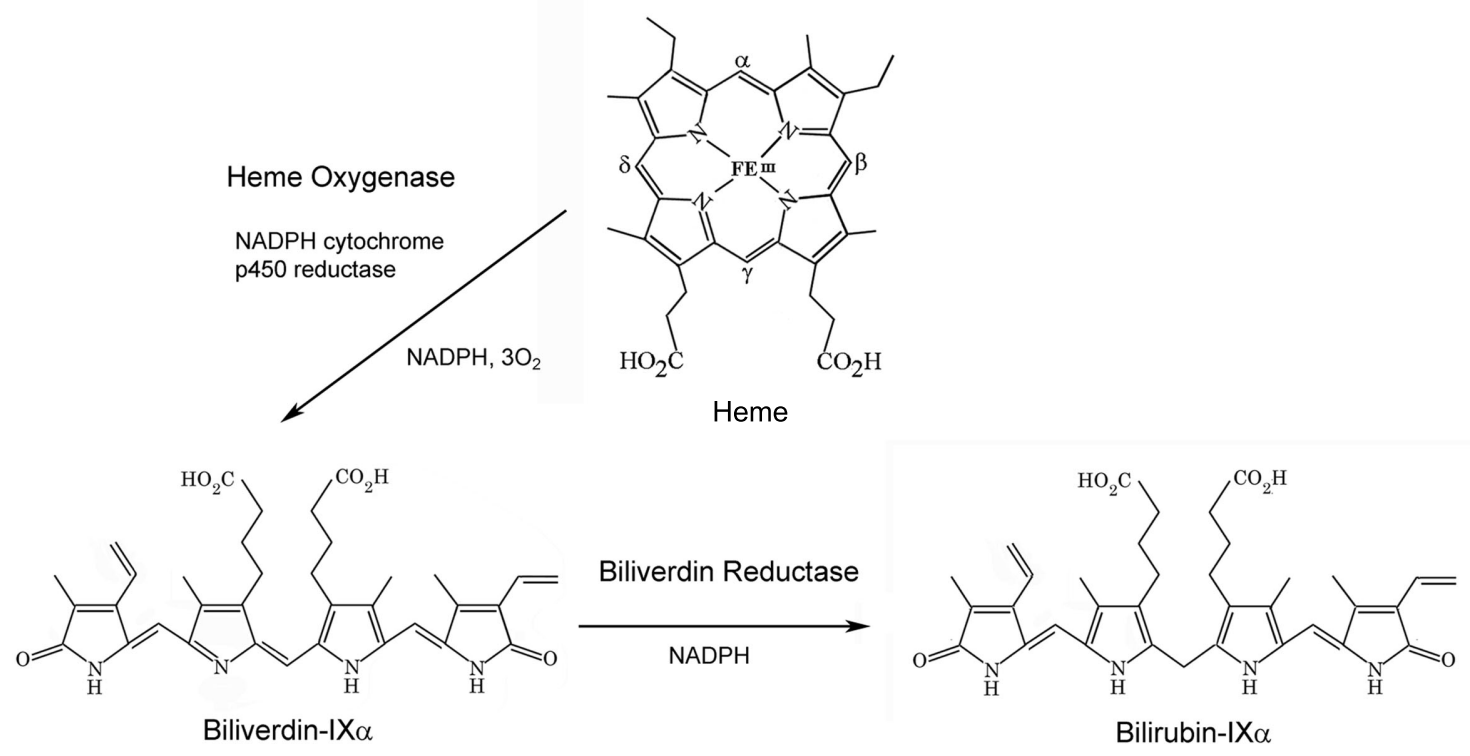

UGT1A1
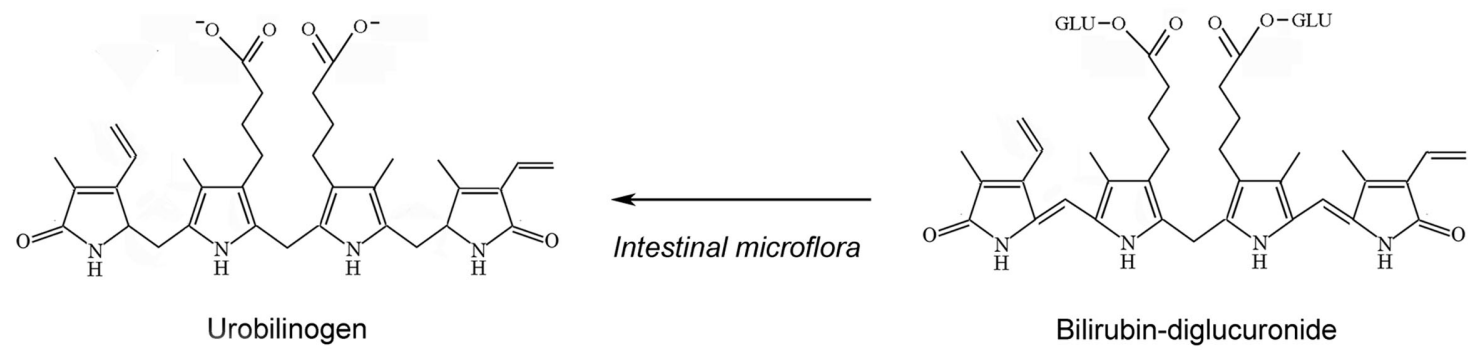

FIGURE 1 | Sequence of bile pigment formation and degradation. Heme Oxygenase (HO) degrades heme to biliverdin-IX $(\mathrm{BV})$, in a reaction generating carbon monoxide $(\mathrm{CO})$ and ferrous iron, at the expense of NADPH and molecular oxygen. $\mathrm{BV}$ is reduced to bilirubin-IX $\alpha(B R)$ by $\mathrm{NAD}(\mathrm{P}) \mathrm{H}$ biliverdin reductase (BVR). BR is conjugated with glucuronic acid at its propionyl side chains by hepatic UDP-glucuronyltransferase-1A1 (UGT1A1), to form BR mono- and di-glucuronides. BR can be further metabolized to urobilinogen by intestinal microflora. of serum unconjugated BR circulates freely $(\sim 0.01 \%$; Vitek and Ostrow, 2009). Unconjugated BR is taken up by the liver by facilitated diffusion, involving organic ion transporters (e.g., SLCO1B1; Kamisako et al., 2000; Cui et al., 2001). The intracellular hepatocyte transport of BR is assisted by ligandin, a complex of glutathione$S$-transferase (GST) subunits, and by protein-Z (Litwack et al., 1971). BR is conjugated in hepatocytes by uridine diphosphate (UDP) glucuronyltransferase (UGT1A1; EC: 2.4.1.17; Chowdhury et al., 1979). Conjugated BR (mono- and di-glucuronides) is pumped from hepatocytes across the canalicular membrane by multidrug resistance protein- 2 and excreted through the bile to the intestine (Chowdhury and Chowdhury, 1983; Wang et al., 2006a).

\section{ANTIOXIDANT EFFECTS OF BILE PIGMENTS}

The potential for the use of bile pigments as therapeutics originated with the discovery that these substances act as natural antioxidants. Stocker et al. demonstrated that BV, BR, and conjugated BR inhibit lipid peroxidation in liposomal preparations challenged with free radical initiating chemicals (Stocker and Ames, 1987; Stocker et al., 1987a; Stocker and Peterhans, 1989a). In these model systems, BR and BV exerted chain-breaking and peroxyl radical trapping activity (Stocker and Ames, 1987; Stocker et al., 1987a). BV and conjugated BR acted as co-antioxidants with $\alpha$-tocopherol, and inhibited $\alpha$-tocopherol consumption (Stocker and Peterhans, 1989a). BR also prevented oxidative damage to proteins, such as serum albumin exposed to ROS-generating systems (Stocker et al., 1987b; Neuzil and Stocker, 1993). Free and albuminbound BR inhibited oxidation of LDL-bound lipids, by acting as co-antioxidants with the LDL-bound $\alpha$-tocopherol (Neuzil and Stocker, 1994).

Bilirubin can react with superoxide anion radical, hypochlorous acid, and singlet molecular oxygen, inhibit the photo-oxidation of protein, and inhibit chemiluminescence in activated macrophages (Stevens and Small, 1976; Pedersen et al., 1977; Stocker and Peterhans, 1989b). BR can also react with $\mathrm{NO}$ or reactive nitrogen species (RNS; Kaur et al., 2003; Mancuso et al., 2003). Finally, conjugated BR forms a cupric complex that promotes decomposition 


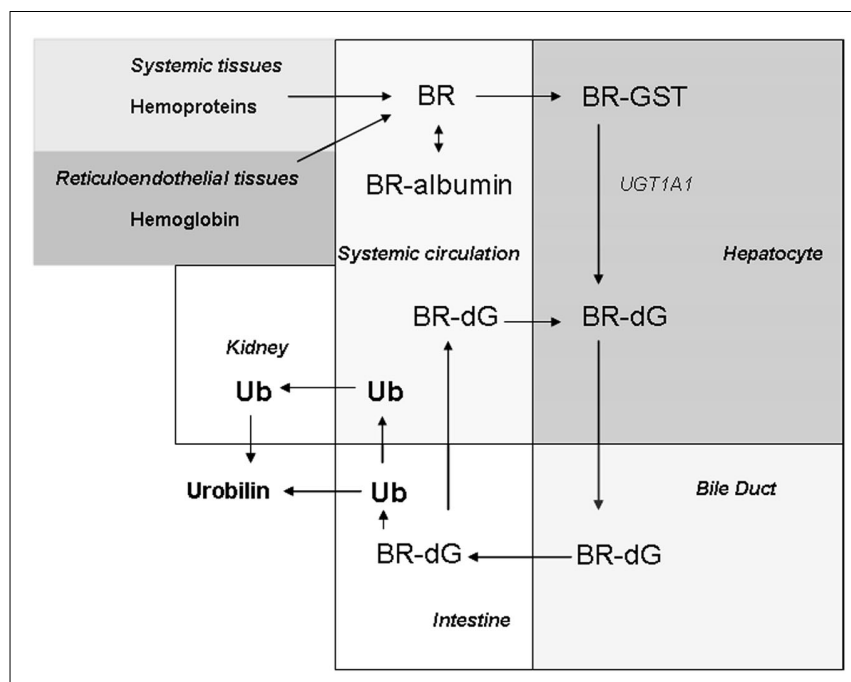

FIGURE 2 | Biodistribution of BR. BR is generated in systemic tissues as the product of hemoprotein (i.e., hemoglobin) degradation. BR formed in tissues passes freely to the circulation, where it exists mostly in a complex with serum albumin. BR is taken up by hepatocytes by facilitated diffusion. In the hepatocyte, BR is transported by glutathione-S-transferase (GST), and then conjugated by UDP-glucuronyltransferase-1A1 (UGT1A1) to form bilirubin di-glucuronide (BR-dG). Conjugated $B R$ (BR-dG) is then pumped into the bile duct and reaches the intestine. Conjugated BR can be reabsorbed in the intestine and re-enter the circulation (Roy-Chowdhury et al., 2008; Vitek and Ostrow, 2009). The metabolism of BR in the intestine by bacterial action generates urobilinogen (UB) and its oxidation product urobilin, the latter which is eliminated in the feces. Intestinal urobilinogen can be reabsorbed by the intestine and eliminated in the urine as urobilin (Chowdhury and Chowdhury, 1983; Wang et al., 2006a).

of hydroperoxides, representing a pro-oxidant activity in the bile (Stocker and Ames, 1987).

Bilirubin serves as circulating antioxidant in human plasma. The treatment of plasma with oxidizing agents resulted in the depletion of endogenous antioxidants in the order ubiquinol-10, ascorbate, and bilirubin. The addition of BR to human plasma after depletion of naturally occurring antioxidants resulted in the inhibition of lipid peroxidation, and reduction of $\alpha$-tocopherol consumption (Neuzil and Stocker, 1994). Serum samples from hyperbilirubinemic patients with Gilbert's syndrome were resistant to oxidation and displayed higher total antioxidant capacity than serum from subjects in the normal range of BR concentration (Bulmer et al., 2008).

Exogenous BR when applied pharmacologically to cultured cells can provide dose-dependent cytoprotection against oxidative stress (Clark et al., 2000a). For example, BR (1-5 $\mu \mathrm{M})$ protected cultured vascular smooth muscle cells against cytotoxicity from enzyme-generated $\mathrm{H}_{2} \mathrm{O}_{2}$ (Clark et al., 2000a). BR when applied at nanomolar concentrations protected primary neurons against cytotoxicity caused by exogenous $\mathrm{H}_{2} \mathrm{O}_{2}$ (Doré et al., 1999).

Despite evidence suggesting that extracellular BR can act as a cytoprotectant, the role of $\mathrm{BR}$ as a cellular antioxidant remains unclear. BR produced in situ is secreted to the circulation, conjugated in the liver, and excreted (Roy-Chowdhury, 1996). However, the fraction of $\mathrm{BR}$ that is retained in cells to serve a membrane antioxidant function is unknown. A common argument against a cellular antioxidant role for BR is that the cellular milieu contains efficient and abundant endogenous antioxidant compounds, including millimolar quantities of reduced glutathione (GSH; Meister and Anderson, 1983), ascorbate, $\beta$-carotene, and $\alpha$-tocopherol (Halliwell and Gutteridge, 1999). Given that BR is exported and eliminated, the relative contribution of BR to cellular antioxidant capacity in the presence of other endogenous antioxidants remains unclear.

Current evidence for the role of BR as a cellular antioxidant is based on evidence using siRNA studies targeting BVR, the enzyme responsible for BR formation. Knockdown of BVR sensitized cells to high concentrations of $\mathrm{H}_{2} \mathrm{O}_{2}$ (Baranano et al., 2002), and to arsenite-mediated apoptosis (Miralem et al., 2005). In the latter case, similar effects were not achieved with HO-1 knockdown, suggesting effects of BVR independent of BR generation (Miralem et al., 2005).

Snyder et al. observed that BV is formed during the oxidation of BR (Baranano et al., 2002). The authors proposed that BV formed by $B R$ oxidation would act as a substrate for BVR, to regenerate $B R$, and thus represent a self-perpetuating antioxidant system, "the BVR antioxidant cycle." Evidence for and against this pathway has been debated elsewhere (Maghzal et al., 2009; Sedlak and Snyder, 2009; Stocker and Maghzal, 2009). It remains unclear if $\mathrm{BV}$ regenerated during the oxidation of BR would exceed but a minor fraction, and whether this would contribute significantly to cellular antioxidant capacity as proposed.

\section{TOXICITY OF BILIRUBIN}

Bilirubin accumulation can be harmful, especially in infants with neonatal hyperbilirubinemia. The selective toxicity of BR to the neonate is due to incomplete establishment of the blood-brain barrier. Neonatal unconjugated hyperbilirubinemia is associated with severe neurological side effects, which include neurological encephalopathy and kernicterus (Vitek and Ostrow, 2009). To avoid risk of neurotoxicity, phototherapy is applied to reduce the levels of unconjugated BR in jaundiced newborns (Blanckaert and Fevery, 1990). The mechanisms of BR toxicity in the brain have been reviewed elsewhere (Brito et al., 2008; Ghersi-Egea et al., 2009; Tell and Gustincich, 2009; Vitek and Ostrow, 2009).

\section{PROTECTIVE EFFECTS OF BILE PIGMENTS IN ANIMAL MODELS OF TISSUE INJURY}

Excluding neonatal toxicity, mild hyperbilirubinemia, due to elevated serum antioxidant capacity, may confer benefits to the host. In a mouse model of hyperbilirubinemia, jaundiced Gunn rats displayed lower indices of oxidative stress in the serum than wild-type mice when challenged with hyperoxia (Dennery et al., 1995).

Therapeutic application of BR preserved myocardial function during cardiac ischemia/reperfusion (I/R) injury (Clark et al., $2000 \mathrm{~b})$. In an isolated perfused heart model, heme preconditioning protected against myocardial infarction following I/R injury, associated with increased $\mathrm{HO}-1$ expression and BR formation. Administration of BR at nanomolar concentrations improved cardiac performance and reduced infarct size and mitochondrial dysfunction following I/R injury (Clark et al., 2000b) 
Injection of $\mathrm{BV}$ decreased pro-inflammatory cytokines production (i.e., IL-6), upregulated IL-10 levels, and reduced inflammatory lung injury in rats challenged with lipopolysaccharide (LPS). Thus, BV protected against systemic inflammation and lung injury after lethal exposure to LPS. The protective effects of BV against LPS-induced injury were observed in cultured lung endothelial cells and macrophages (Sarady-Andrews et al., 2005). Additional anti-inflammatory effects of BR have been reported in cell culture. For example, BR inhibited TNF- $\alpha$ dependent expression of adhesion molecules (i.e., E-selectin, VCAM-1, ICAM-1) in endothelial cells (Mazzone et al., 2009). Recently, enhanced nuclear translocation of BVR has been implicated in the anti-inflammatory effects of BV (Wegiel et al., 2011).

Bilirubin can act as an inhibitor of smooth muscle cell proliferation (Nakao et al., 2005; Ollinger et al., 2005). Exogenous BV administration inhibited neointimal hyperplasia associated with vascular injury in rats (Nakao et al., 2005; Ollinger et al., 2005). These effects were attributed to downregulation of JNK, and inhibition of endothelial cell apoptosis (Nakao et al., 2005). Similarly, hyperbilirubinemic animals were resistant to vascular injury (Ollinger et al., 2005). The anti-proliferative effects of BV and BR were demonstrated in vascular smooth muscle cell culture. Exogenous BV/BR arrested cells in $\mathrm{G}_{1}$ phase after serum stimulation, associated with inhibition of p38 MAPK and retinoblastoma protein phosphorylation (Ollinger et al., 2005).

Experimental hyperbilirubinemia $(3-10 \mathrm{mg} / \mathrm{dl})$ induced by infusion protected against bleomycin-induced pulmonary fibrosis in rats (Wang et al., 2002). BR-infused rats displayed reduced lung injury in response to bleomycin challenge, including lowered lung hydroxyproline content, reduced polymorphonuclear lymphocyte and leukocyte counts, and reduced levels of transforming growth factor- $\beta$ in bronchoalveolar lavage (Wang et al., 2002). Thus, the anti-fibrotic effects of BR may relate to both antioxidant and anti-proliferative effects of this pigment.

Recent studies have also implied a protective effect of BV/BR in diabetes. Application of BV to streptozotocin induced diabetic rats reduced urinary isoprostanes, and protected against endothelial cell sloughing (Rodella et al., 2006). BR ameliorated diabetic nephropathy, through the reduction of cytosolic ROS generation and anti-inflammatory effects (Fujii et al., 2010). Hyperbilirubinemic mice, or BV-treated diabetic mice, displayed reduced albuminuria, and urinary markers of oxidative stress relative to wild-type or untreated controls, respectively. Application of BV or BR inhibited ROS production in endothelial and mesangial cells induced by high glucose or angiotensin-II exposure (Fujii et al., 2010).

\section{PROTECTIVE EFFECTS OF BILE PIGMENTS IN ORGAN TRANSPLANTATION}

Therapeutic effects of exogenously applied bile pigments have been described in animal models of organ transplantation and acute graft rejection, including liver (Fondevila et al., 2004), kidney (Adin et al., 2005), and heart (Yamashita et al., 2004) transplantation. In the isolated perfused kidney, perfusion with BR protected against warm I/R-induced tissue injury and preserved renal function (Adin et al., 2005). BV provided tissue protection in an ex vivo model of cold hepatic I/R injury. Furthermore, inclusion of BV in the perfusate increased survival in rats subjected to orthotopic liver transplantation by preserving liver function (Fondevila et al., 2004). This protection conferred by BV was associated with decreased expression of pro-inflammatory indices, including neutrophil influx, pro-inflammatory cytokine expression, and iNOS activation (Fondevila et al., 2004). BV treatment improved survival of rat cardiac allografts, by reducing leukocyte infiltration and inhibiting T-cell proliferation (Yamashita et al., 2004). In transplant-associated cold I/R injury of heart and kidney grafts, the application of BV simultaneously with CO provided a synergistic tissue protection, whereas lesser effects were observed with either test agent alone (Nakao et al., 2000). BV also prevented rejection of lung grafts from brain-dead donors, which are more prone to rejection (Zhou et al., 2011). In allogeneic islet transplantation, treatment of the donor or the donor graft ex vivo with BR improved islet graft survival. Treatment of the recipient with BR also improved the survival of islet grafts (Wang et al., 2006b; Zhu et al., 2010). BR conferred transplant tolerance to islet grafts by up-regulating regulatory $\mathrm{T}$ cells (Lee et al., 2007). The antiapoptotic and anti-inflammatory effects of BV/BR observed in I/R injury models may contribute to protection during I/R injury associated with transplantation. These experiments also suggest that pharmacological BR may have immunomodulatory functions that contribute to therapeutic effects in the setting of graft rejection (Ollinger et al., 2007).

\section{BILIRUBIN IN CARDIOVASCULAR AND LUNG DISEASE}

Recent clinical studies have reported inverse associations between serum BR levels and the risk factors associated with CVD. These studies collectively suggest that natural elevations in serum BR confer protection against CVD, including atherosclerosis, coronary artery disease (CAD)/ischemic heart disease (IHD), diabetes, and stroke (Novotný and Vítek, 2003; Franchini et al., 2010).

In one of the first studies reporting associations between BR and CVD, a study of 619 males adjusted for age-dependent risk factors, the level of serum BR was described as an inverse risk factor for CAD (Schwertner et al., 1994). BR was weakly predictive for CAD relative to lipoprotein markers (Levinson, 1997). Nevertheless, a strong correlation between BR levels and apolipoprotein $B$ levels, a risk factor for atherosclerosis, was reported (Levinson, 1997). Serum BR levels represented an inverse risk factor for CAD in subjects with early familial CAD (Hopkins et al., 1996).

In a large-scale prospective study (7,685 men), subjects in the midrange of serum BR concentration displayed reduced risk of IHD, relative to subjects in the lowest quintile of serum BR distribution (Breimer et al., 1995). Individuals in the lowest BR quintile exhibited reduced high density lipoprotein (HDL) cholesterol, and reduced lung function. Although midlevel serum BR was associated with reduced CVD risk, the hyperbilirubinemic individuals (highest quintile) exhibited a similar risk of IHD as individuals in the lowest serum BR quintile (Breimer et al., 1995).

Serum BR levels have been indicated as an independent, inverse risk factor for peripheral vascular disease (Breimer et al., 1994). In large-scale cross-sectional studies, serum BR levels within the normal range were inversely associated with risk of peripheral vascular disease (Perlstein et al., 2008a) and stroke (Perlstein et al., 2008b). A $1.71 \mu \mathrm{M}$ increase in BR level was associated with $6 \%$ reduction 
in the odds of peripheral vascular disease (7,075 participants; Perlstein et al., 2008a), and 9\% reduction in the odds of stroke (13,214 participants; Perlstein et al., 2008b).

In 72 healthy subjects, serum BR levels were inversely correlated with indicators for atherosclerosis (Erdogan et al., 2005). Low serum BR levels were associated with increased carotid artery intimal-medial thickness, and impaired flow-mediated vasodilation, indicative of endothelial dysfunction (Erdogan et al., 2005). Furthermore, BR levels were inversely correlated to carotid plaque formation in 1,774 subjects, with a reported odds ratio of 0.37 for an increase of $17.1 \mu \mathrm{M}$ increase in BR (Ishizaka et al., 2001).

In a cross-sectional study of 2,307 Koreans, total and direct BR levels were inversely correlated to plasma levels of C-reactive protein (CRP), an indicator of vascular inflammation (Hwang et al., 2011). Similar inverse associations were reported between BR and levels of high sensitivity (hs)-CRP (Gullu et al., 2005; Yoshino et al., 2011). BR was inversely correlated with CVD in patients with hypercholesterolemia, and elevated in patients receiving statins (Nolting et al., 2011).

A prospective study (Framingham offspring study, 5,124 participants) concluded that a higher concentration of total serum BR was associated with lower risk of CVD in men, with unclear association for women (Djousse et al., 2001). This study revealed a higher risk of myocardial infarction for both men and women associated with low serum BR and low serum albumin (Djoussé et al., 2003).

Bilirubin levels have been examined as an independent predictor of CVD mortality. No association was found between serum BR and all-cause CVD mortality in a 10 year study of the Belgian population, although increased BR was associated with reduced cancer mortality in males (Temme et al., 2001). However, in a recently published study of 1,279 men, BR levels and cardiopulmonary fitness level was independently and negatively correlated to all-cause and CVD mortality (Ajja et al., 2011).

Additional studies have analyzed potential associations between BR levels and CVD-related diseases such as diabetes (Ko et al., 1996; Fukui et al., 2008, 2011; Cheriyath et al., 2010) and metabolic syndrome (Jo et al., 2011; Kwon et al., 2011). A large cross-sectional study (15,876 subjects) reported an inverse association between total BR and diabetes risk (Cheriyath et al., 2010). Patients with type II diabetes on hemodialysis displayed an increased risk of CVD associated with low serum BR, relative to diabetic patients not on hemodialysis (Fukui et al., 2011). Serum BR was inversely correlated with albuminuria in Type II diabetic patients (Fukui et al., 2008). In a Chinese cohort (1,508 subjects), low serum BR was associated with aberrations in glucose tolerance, and increases in CVD risk factors including triglycerides, very-low density lipoprotein, and glycated hemoglobin (Ko et al., 1996).

Additional studies have examined associations of BR with CVD in hyperbilirubinemia originating from metabolic disorders of BR metabolism. A TA repeat polymorphism of the UTG1A1 gene promoter (designated UGT1A1 $* 28$, or TA7) results in reduced transcription of UTG1A and deficit in hepatic BR conjugation and clearance (Schwertner and Vítek, 2008). Individuals homozygous for UGT1A1*28 (TA7/TA7) display a hyperbilirubinemia, referred to as Gilbert's syndrome, relative to wild-type subjects (TA6/TA6) or heterozygotes. A sixfold reduced risk of IHD and elevated HDL cholesterol was reported in a study of 50 Gilbert's patients relative to the general population (Vitek et al., 2002). In Gilbert's patients, unconjugated BR was negatively correlated with small dense low density lipoprotein cholesterol sd-LDL-C, oxidized LDL and hs-CRP (Tapan et al., 2011).

In the Framingham Heart study homozygote carriers for the UGT1A1 $* 28$ allele with elevated serum BR concentrations displayed a strong association with lower CVD risk (Lin et al., 2006). These observations were further validated by conditional linkage and genome-wide association studies. These studies concluded that UTG1A is a major gene linked to CVD, and that the TA repeat polymorphism is strongly associated with reduced CVD risk (Lin et al., 2009). In a study of peripheral arterial disease, no association of UGT1A1 polymorphisms was observed, despite inverse correlation of CVD risk with BR levels (Rantner et al., 2008). Recent post-mortem studies also reported that UGT1A1 polymorphisms were not correlated with severity of CAD (Papez et al., 2009).

Finally, BR was inversely associated with risk of lung disease. In a cohort study $(504,206$ subjects) each $0.1-\mathrm{mg} / \mathrm{dL}$ increase in $\mathrm{BR}$ in males was associated with $9 \%$, and $6 \%$ decreases in the risk of lung cancer, and chronic obstructive pulmonary disease, respectively (Horsfall et al., 2011).

\section{CONCLUSION}

Biliverdin and BR are naturally occurring substances derived from heme catabolism that possess antioxidant properties. Furthermore, circulating BR can contribute to serum antioxidant capacity. In pre-clinical studies, pharmacological application of BR confers protection against I/R injury, acute lung injury, pulmonary fibrosis, renal injury, and graft rejection. Several limitations of the therapeutic applications of bile pigments must be considered. Although BV is soluble in aqueous media, BR is lipophilic and soluble only in organic solvents, thereby posing challenges for therapeutic delivery.

Bilirubin is the by-product of the heme degradation pathway, and thereby may mediate the cytoprotective properties of $\mathrm{HO}-1$ (Foresti et al., 2004). Pharmacological or gene therapy approaches involving the targeted expression of $\mathrm{HO}-1$ are under development (Abraham et al., 2007). However, these approaches are not specific for BV/BR generation, since modulation of HO-1 has pleiotropic effects that impact systemic iron metabolism and CO generation. Similarly, targeted expression of BVR may affect cellular signaling pathways independently of its role in bile pigment generation (Kapitulnik and Maines, 2009). Clinical studies have suggested inverse associations between serum BR and CVD risk. Mild hyperbilirubinemia may reduce CVD risk, but this awaits further validation. To date, there remain no practical methodologies for inducing hyperbilirubinemia for clinical benefit. Despite therapeutic benefit in animal tissue injury models, the therapeutic potential of BR remains untested in humans.

\section{ACKNOWLEDGMENTS}

Dr. Ryter wishes to acknowledge current and former colleagues who have contributed to some of the referenced works described herein. Dr. Ryter currently holds a faculty appointment at the Brigham and Women's Hospital (BWH), Boston, and is an Adjunct Scientist of the Lovelace Respiratory Research Institute (LRRI), Albuquerque, New Mexico. In this capacity, Dr. Ryter received salary support from the LRRI/BWH consortium for lung research. 


\section{REFERENCES}

Abraham, N. G., Asija, A., Drummond, G., and Peterson, S. (2007). Heme oxygenase-1 gene therapy: recent advances and therapeutic applications. Curr. Gene Ther. 7, 89-108.

Adin, C. A., Croker, B. P., and Agarwal, A. (2005). Protective effects of exogenous bilirubin on ischemiareperfusion injury in the isolated, perfused rat kidney. Am. J. Physiol. Renal Physiol. 288, F778-F784.

Ajja, R., Lee, D. C., Sui, X., Church, T. S., and Steven, N. B. (2011). Usefulness of serum bilirubin and cardiorespiratory fitness as predictors of mortality in men. Am. J. Cardiol. 108, 1438-1442.

Baranano, D. E., Rao, M., Ferris, C. D., and Snyder, S. H. (2002). Biliverdin reductase: a major physiologic cytoprotectant. Proc. Natl. Acad. Sci. U.S.A. 99, 16093-16098.

Blanckaert, N., and Fevery, J. (1990). "Physiology and pathophysiology of bilirubin metabolism," in Hepatology. A Textbook of Liver Disease, 2nd Edn, Vol. 1, eds D. Zakim and T. D. Boyer (Philadelphia: W. D. Saunders), 254-302.

Breimer, L. H., Spyropolous, K. A., Winder, A. F., Mikhailidis, D. P., and Hamilton, G. (1994). Is bilirubin protective against coronary artery disease. Clin. Chem. 40, 1987-1988.

Breimer, L. H., Wannamethee, G., Ebrahim, S., and Shaper, A. G. (1995). Serum bilirubin and risk of ischemic heart disease in middleaged British men. Clin. Chem. 41, 1504-1508.

Brito, M. A., Lima, S., Fernandes, A., Falcão, A. S., Silva, R. F., Butterfield, D. A., and Brites, D. (2008). Bilirubin injury to neurons: contribution of oxidative stress and rescue by glycoursodeoxycholic acid. Neurotoxicology 29, 259-269.

Bulmer, A. C., Blanchfield, J. T., Toth, I., Fassett, R. G., and Coombes, J. S. (2008). Improved resistance to serum oxidation in Gilbert's syndrome: a mechanism for cardiovascular protection. Atherosclerosis 199, 390-396.

Cheriyath, P., Gorrepati, V. S., Peters, I., Nookala, V., Murphy, M. E., Srouji, N., and Fischman, D. (2010). High total bilirubin as a protective factor for diabetes mellitus: an analysis of NHANES data from 1999-2006. J. Clin. Med. Res. 2, 201-216.

Chowdhury, J. R., and Chowdhury, N. R. (1983). Conjugation and excretion of bilirubin. Semin. Liver Dis. 3, 11-23.

Chowdhury, J. R., Chowdhury, N. R., Bhargava, M. M., and Arias, I.
M. (1979). Purification and partial characterization of rat liver bilirubin glucuronoside glucuronosyltransferase. J. Biol. Chem. 254, 8336-8339.

Clark, J. E., Foresti, R., Green, C. J., and Motterlini, R. (2000a). Dynamics of haem oxygenase-1expression and bilirubin production in cellular protection against oxidative stress. Biochem. J. 348, 615-619.

Clark, J. E., Foresti, R., Sarathchandra, P., Kaur, H., Green, C. J., and Motterlini, R. (2000b). Heme oxygenase-1derived bilirubin ameliorates postischemic myocardial dysfunction. Am. J. Physiol. 278, H643-H651.

Cui, Y., König, J., Leier, I., Buchholz, U., and Keppler, D. (2001). Hepatic uptake of bilirubin and its conjugates by the human organic anion transporter SLC21A6. J. Biol. Chem. 276, 9626-9630.

Davies, K. J. (1995). Oxidative stress: the paradox of aerobic life. Biochem. Soc. Symp. 61, 1-31.

Davies, K. J. (2000). Oxidative stress, antioxidant defenses, and damage removal, repair, and replacement systems. IUBMB Life 50, 279-289.

Dennery, P. A., McDonagh, A. F., Spitz, D. R., Rodgers, P. A., and Stevenson, D. K. (1995). Hyperbilirubinemia results in reduced oxidative injury in neonatal Gunn rats exposed to hyperoxia. Free Radic. Biol. Med. 19, 395-404.

Djousse, L., Levy, D., Cupples, L. A., Evans, J. C., D'Agostino, R. B., and Ellison, R. C. (2001). Total serum bilirubin and risk of cardiovascular disease in the Framingham Offspring Study. Am. J. Cardiol. 87, 1196-1200.

Djoussé, L., Rothman, K. J., Cupples, L. A., Levy, D., and Ellison, R. C. (2003). Effect of serum albumin and bilirubin on the risk of myocardial infarction (the Framingham Offspring Study). Am. J. Cardiol. 91, 485-488.

Doré, S., Takahashi, M., Ferris, C. D., Zakhary, R., Hester, L. D., Guastella, D., and Snyder, S. H. (1999). Bilirubin, formed by activation of heme oxygenase-2, protects neurons against oxidative stress injury. Proc. Natl. Acad. Sci. U.S.A. 96, 2445-2450.

Dröge, W. (2002). Free radicals in the physiological control of cell function. Physiol. Rev. 82, 47-95.

Erdogan, D., Gullu, H., Yildirim, E., Tok, D., Kirabas, I., Ciftci, O., Baycan, S. T., and Muderrisoglu, H. (2005). Low serum bilirubin levels are independently and inversely related to impaired flow-mediated vasodilation and increased carotid intima-media thickness in both men and women. Atherosclerosis 184 431-437.

Fondevila, C., Shen, X. D., Tsuchiyashi, S., Yamashita, K., Csizmadia, E., Lassman, C., Busuttil, R. W., KupiecWeglinski, J. W., and Bach, F. H. (2004). Biliverdin therapy protects rat livers from ischemia and reperfusion injury. Hepatology 40, 1333-1341.

Foresti, R., Green, C. J., and Motterlini, R. (2004). Generation of bile pigments by haem oxygenase: a refined cellular strategy in response to stressful insults. Biochem. Soc. Symp. 71, 177-192.

Forman, H. J., Maiorino, M., and Ursini, F. (2010). Signaling functions of reactive oxygen species. Biochemistry 49, 835-842.

Franchini, M., Targher, G., and Lippi, G. (2010). Serum bilirubin levels and cardiovascular disease risk: a Janus Bifrons? Adv. Clin. Chem. 50, 47-63.

Fujii, M., Inoguchi, T., Sasaki, S., Maeda, Y., Zheng, J., Kobayashi, K., and Takayanagi, R. (2010). Bilirubin and biliverdin protect rodents against diabetic nephropathy by downregulating $\mathrm{NAD}(\mathrm{P}) \mathrm{H}$ oxidase. Kidney Int 78, 905-919.

Fukui, M., Tanaka, M., Shiraishi, E. Harusato, I., Hosoda, H., Asano, M., Hasegawa, G., and Nakamura, N. (2008). Relationship between serum bilirubin and albuminuria in patients with type 2 diabetes. Kidney Int. 74, 1197-1201.

Fukui, M., Tanaka, M., Yamazaki, M., Hasegawa, G., Nishimura, M., Iwamoto, N., Ono, T., Imai, S. and Nakamura, N. (2011). Low serum bilirubin concentration in haemodialysis patients with Type 2 diabetes. Diabet. Med. 28, 96-99.

García-Lafuente, A., Guillamón, E., Villares, A., Rostagno, M. A., and Martínez, J. A. (2009). Flavonoids as anti-inflammatory agents: implications in cancer and cardiovascular disease. Inflamm. Res. 58, 537-552.

Ghersi-Egea, J. F., Gazzin, S., and Strazielle, N. (2009). Blood-brain interfaces and bilirubin-induced neurological diseases. Curr. Pharm. Des. 15, 2893-2907.

Gullu, H., Erdogan, D., Tok, D., Topcu, S., Caliskan, M., Ulus, T., and Muderrisoglu, H. (2005). High serum bilirubin concentrations preserve coronary flow reserve and coronary microvascular functions. Arterioscler. Thromb. Vasc. Biol. 25, 2289-2294.

Halliwell, B., and Gutteridge, J. M. C. (1999). Free Radicals in Biology and
Medicine. New York, NY: Oxford University Press.

Hopkins, P. N., Wu, L. L., Hunt, S. C., James, B. C., Vincent, G. M., and Williams, R. R. (1996). Higher serum bilirubin is associated with decreased risk for early familial coronary artery disease. Arterioscler. Thromb. Vasc. Biol. 16, 250-255.

Horsfall, L. J., Rait, G., Walters, K., Swallow, D. M., Pereira, S. P., Nazareth, I., and Petersen, I. (2011). Serum bilirubin and risk of respiratory disease and death. JAMA 305, 691-697.

Hwang, H. J., Lee, S. W., and Kim, S. H. (2011). Relationship between bilirubin and C-reactive protein. Clin. Chem. Lab. Med. 49, 1823-1828.

Ishizaka, N., Ishizaka, Y., Takahashi, E., Yamakado, M., and Hashimoto, H. (2001). High serum bilirubin level is inversely associated with the presence of carotid plaque. Stroke 32, 580-583.

Jo, J., Yun, J. E., Lee, H., Kimm, H., and Jee, S. H. (2011). Total, direct, and indirect serum bilirubin concentrations and metabolic syndrome among the Korean population. Endocrine 39, 182-189.

Kaliora, A. C., Dedoussis, G. V., and Schmidt, H. (2006). Dietary antioxidants in preventing atherogenesis. Atherosclerosis 187, 1-17.

Kamisako, T., Kobayasi, Y., Takeuchi, K., Ishihara, T., Higuchi, K., Tanaka, Y., Gabazza, E. C., and Adachi, Y. (2000). Recent advances in bilirubin metabolism research: the molecular mechanism of hepatocyte bilirubin transport and its clinical relevance. J. Gastroenterol. 35, 659-664.

Kapitulnik, J., and Maines, M. D. (2009). Pleiotropic functions of biliverdin reductase: cellular signaling and generation of cytoprotective and cytotoxic bilirubin. Trends Pharmacol. Sci. 30, 129-137.

Kaur, H., Hughes, M. N., Green, C. J., Naughton, P., Foresti, R., and Motterlini, R. (2003). Interaction of bilirubin and biliverdin with reactive nitrogen species. FEBS Lett. 543, 113-119.

Ko, G. T., Chan, J. C., Woo, J., Lau, E., Yeung, V. T., Chow, C. C., Li, J. K., So, W. Y., and Cockram, C. S. (1996). Serum bilirubin and cardiovascular risk factors in a Chinese population. J. Cardiovasc. Risk 3, 459-463.

Kwon, K. M., Kam, J. H., Kim, M. Y., Kim, M. Y., Chung, C. H., Kim, J. K., Linton, J. A., Eom, A., Koh, S. B. and Kang, H. T. (2011). Inverse association between total bilirubin and metabolic syndrome in rural korean women. J. Womens Health (Larchmt) 20, 963-969. 
Lee, S. S., Gao, W., Mazzola, S., Thomas, M. N., Csizmadia, E., Otterbein, L. E., Bach, F. H., and Wang, H. (2007). Heme oxygenase-1, carbon monoxide, and bilirubin induce tolerance in recipients toward islet allografts by modulating $\mathrm{T}$ regulatory cells. FASEB J. 21, 3450-3457.

Levinson, S. S. (1997). Relationship between bilirubin, apolipoprotein B, and coronary artery disease. Ann. Clin. Lab. Sci. 27, 185-192.

Lin, J. P., O’Donnell, C. J., Schwaiger, J. P., Cupples, L. A., Lingenhel, A., Hunt, S. C., Yang, S., and Kronenberg, F. (2006). Association between the UGT1A1 $* 28$ allele, bilirubin levels, and coronary heart disease in the Framingham Heart Study. Circulation 114, 1476-1481.

Lin, J. P., Schwaiger, J. P., Cupples, L. A., O’Donnell, C. J., Zheng, G., Schoenborn, V., Hunt, S. C., Joo, J., and Kronenberg, F. (2009). Conditional linkage and genome-wide association studies identify UGT1A1 as a major gene for anti-atherogenic serum bilirubin levels-the Framingham Heart Study. Atherosclerosis 206, 228-233.

Litwack, G., Ketterer, B., and Arias, I. M. (1971). Ligandin: a hepatic protein which binds steroids, bilirubin, carcinogens and number of exogenous organic anions. Nature 234, 466-467.

Maghzal, G. J., Leck, M. C., Collinson, E., Li, C., and Stocker, R. (2009). Limited role for the bilirubin-biliverdin redox amplification cycle in the cellular antioxidant protection by biliverdin reductase. J. Biol. Chem. 284, 29251-29259.

Maines, M. D. (1997). The heme oxygenase system: a regulator of second messenger gases. Annu. Rev. Pharmacol. Toxicol. 37, 517-554.

Mancuso, C., Bonsignore, A., Di Stasio, E., Mordente, A., and Motterlini, R. (2003). Bilirubin and S-nitrosothiols interaction: evidence for a possible role of bilirubin as a scavenger of nitric oxide. Biochem. Pharmacol. 66, 2355-2363.

Mazzone, G. L., Rigato, I., Ostrow, J. D., Bossi, F., Bortoluzzi, A., Sukowati, C. H., Tedesco, F., and Tiribelli, C. (2009). Bilirubin inhibits the TNFalpha-related induction of three endothelial adhesion molecules. Biochem. Biophys. Res. Commun. 386, 338-344.

Meister, A., and Anderson, M. E. (1983). Glutathione. Annu. Rev. Biochem. 52, 711-760.

Miralem, T., Hu, Z., Torno, M. D., Lelli, K. M., and Maines, M. D.
(2005). Small interference RNAmediated gene silencing of human biliverdin reductase, but not that of heme oxygenase-1, attenuates arsenite-mediated induction of the oxygenase and increases apoptosis in 293A kidney cells. J. Biol. Chem. 280, 17084-17092.

Nakao, A., Murase, N., Ho, C., Toyokawa, H., Billiar, T. R., and Kanno, S. (2005). Biliverdin administration prevents the formation of intimal hyperplasia induced by vascular injury. Circulation 112, 587-591.

Nakao, A., Neto, J. S., Kanno, S., Stolz, D. B., Kimizuka, K., Liu, F., Bach, F. H., Billiar, T. R., Choi, A. M., Otterbein, L. E., and Murase, N. (2000). Protection against ischemia/reperfusion injury in cardiac and renal transplantation with carbon monoxide, biliverdin and both. Am. J. Transplant. 5, 282-291.

Neuzil, J., and Stocker, R. (1993). Bilirubin attenuates radical-mediated damage to serum albumin. FEBS Lett. 331, 281-284.

Neuzil, J., and Stocker, R. (1994). Free and albumin-bound bilirubin are efficient co-antioxidants for alpha-tocopherol, inhibiting plasma and low density lipoprotein lipid peroxidation. J. Biol. Chem. 269, 16712-16719.

Noguchi, M., Yoshida, T., and Kikuchi, G. (1979). Specific requirement of NADPH-cytochrome $\mathrm{c}$ reductase for the microsomal heme oxygenase reaction yielding biliverdin IX alpha. FEBS Lett. 98, 281-284.

Nolting, P. R., Kusters, D. M., Hutten, B. A., Kastelein, J. J., and ExPRESS study group. (2011). Serum bilirubin levels in familial hypercholesterolemia: a new risk marker for cardiovascular disease? J. Lipid Res. 52, 1755-1759.

Novotný, L., and Vítek, L. (2003). Inverse relationship between serum bilirubin and atherosclerosis in men: a meta-analysis of published studies. Exp. Biol. Med. (Maywood) 228, 568-571.

Ollinger, R., Bilban, M., Erat, A., Froio, A., McDaid, J., Tyagi, S., Csizmadia, E., Graca-Souza, A. V., Liloia, A., Soares, M. P., Otterbein, L. E., Usheva, A., Yamashita, K., and Bach, F. H. (2005). Bilirubin: a natural inhibitor of vascular smooth muscle cell proliferation. Circulation 112 , 1030-1039.

Ollinger, R., Wang, H., Yamashita, K., Wegiel, B., Thomas, M., Margreiter, R., and Bach, F. H. (2007). Therapeutic applications of bilirubin and biliverdin in transplantation. Antioxid. Redox Signal. 9, 2175-2185.

Papez, M. J., Civalier, C. J., Thorne, L. B., and Gulley, M. L. (2009). UGT1A1 promoter genotype is not strongly associated with severity of coronary artery disease. Diagn. Mol. Pathol. 18, 226-231.

Pedersen, A. O., Shonheyder, F., and Broderson, R. (1977). Photooxidation of human serum albumin and its complex with bilirubin. Eur. J. Biochem. 72, 213-221.

Perlstein, T. S., Pande, R. L., Beckman, J. A., and Creager, M. A. (2008a). Serum total bilirubin level and prevalent lower-extremity peripheral arterial disease: National Health and Nutrition Examination Survey (NHANES) 1999 to 2004. Arterioscler. Thromb. Vasc. Biol. 28, 166-172.

Perlstein, T. S., Pande, R. L., Creager, M. A., Weuve, J., and Beckman, J. A. (2008b). Serum total bilirubin level, prevalent stroke, and stroke outcomes: NHANES 1999-2004. Am. J. Med. 121, 781-788.

Rantner, B., Kollerits, B., AnderwaldStadler, M., Klein-Weigel, P., Gruber, I., Gehringer, A., Haak, M. Schnapka-Köpf, M., Fraedrich, G., and Kronenberg, F. (2008). Association between the UGT1A1 TArepeat polymorphism and bilirubin concentration in patients with intermittent claudication: results from the CAVASIC study. Clin. Chem. 54, 851-857.

Rodella, L., Lamon, B. D., Rezzani, R., Sangras, B., Goodman, A. I., Falck, J. R., and Abraham, N. G. (2006). Carbon monoxide and biliverdin prevent endothelial cell sloughing in rats with type I diabetes. Free Radic. Biol. Med. 40, 2198-2205.

Roy-Chowdhury, J.(1996). "Bilirubin metabolism and its disorders," in Hepatology. A Textbook of Liver Disease, 3rd Edn, Vol. 1, eds D. Zakim and T. D. Boyer (Philadelphia: W. D. Saunders), 323-361.

Roy-Chowdhury, N., Lu, Y., and RoyChowdhury, J. (2008) "Bilirbuin metabolism," in Textbook of Hepatology: From Basic Science to Clinical Practice, 3rd Edn, eds J. Rodés, J. P. Benhamou, A. T. Blei, J. Reichen, and M. Rizzetto (Hoboken, NJ: Wiley), 165-174.

Ryter, S. W., Morse, D., and Choi, A. M. (2007). Carbon monoxide and bilirubin: potential therapies for pulmonary/vascular injury and disease. Am. J. Respir. Cell Mol. Biol. 36, 175-182.

Sarady-Andrews, J. K., Liu, F., Gallo, D. Nakao, A., Overhaus, M., Ollinger,
R., Choi, A. M., and Otterbein, L. E. (2005). Biliverdin administration protects against endotoxin-induced acute lung injury in rats. Am. J. Physiol. Lung Cell Mol. Physiol. 289, L1131-L1137.

Schwertner, H. A., Jackson, W. G., and Tolan, G. (1994). Association of low serum concentration of bilirubin with increased risk of coronary artery disease. Clin. Chem. 40 , 18-23.

Schwertner, H. A., and Vítek, L. (2008). Gilbert syndrome, UGT1A1*28 allele, and cardiovascular disease risk: possible protective effects and therapeutic applications of bilirubin. Atherosclerosis 198, 1-11.

Sedlak, T. W., and Snyder, S. H. (2009). Cycling the wagons for biliverdin reductase. J. Biol. Chem. 284, le11.

Stevens, B., and Small, R. D. (1976). The photoperoxidation of unsaturated organic molecules-XV. O2 $1 \Delta \mathrm{g}$ quenching by bilirubin and biliverdin. Photochem. Photobiol. 23, 33-36.

Stocker, R., and Ames, B. (1987). Potential role of conjugated bilirubin and copper in the metabolism of lipid peroxides in the bile. Proc. Natl. Acad. Sci. U.S.A. 84, 8130-8134.

Stocker, R., and Maghzal, G. J. (2009). Reply to Sedlak and Snyder: the little bighorn of the biliverdin reductase amplification cycle. J. Biol. Chem. 284, le12.

Stocker, R., and Peterhans, E. (1989a). Synergistic interaction between vitamin $\mathrm{E}$ and the bile pigments bilirubin and biliverdin. Biochim. Biophys. Acta 1002, 238-244.

Stocker, R., and Peterhans, E. (1989b). Antioxidant properties of conjugated bilirubin and biliverdin: relevant scavenging of hypochlorous acid. Free Radic. Res. Commun. 6, 57-66.

Stocker, R., Yamamoto, Y., McDonagh, A., Glazer, A., and Ames, B. N. (1987a). Bilirubin is an antioxidant of possible physiological importance. Science 235, 1043-1045.

Stocker, R., Glazer, A. N., and Ames, B. N. (1987b). Antioxidant activity of albumin-bound bilirubin. Proc. Natl. Acad. Sci. U.S.A. 84, 5918-5922.

Sugamura, K., and Keaney, J. F. Jr. (2011). Reactive oxygen species in cardiovascular disease. Free Radic. Biol. Med. 51, 978-992.

Tapan, S., Karadurmus, N., Dogru, T., Ercin, C. N., Tasci, I., Bilgi, C., Kurt, I., and Erbil, M. K. (2011). Decreased small dense LDL levels in Gilbert's syndrome. Clin. Biochem. 44, 300-303. 
Tell, G., and Gustincich, S. (2009). Redox state, oxidative stress, and molecular mechanisms of protective and toxic effects of bilirubin on cells. Curr. Pharm. Des.15, 2908-2914.

Temme, E. H. M., Zhang, J. J., Schouten, E. G., and Kesteloot, H. (2001). Serum bilirubin and 10-year mortality risk in a Belgian population. Cancer Causes Control 12, 887-894.

Tenhunen, R., Marver, H. S., and Schmid, R. (1969). Microsomal heme oxygenase. Characterization of the enzyme. J. Biol. Chem. 244, 6388-6394.

Tenhunen, R., Ross, M. E., Marver, H. S., and Schmid, R. (1970). Reduced nicotinamide-adenine dinucleotide phosphate dependent biliverdin reductase: partial purification and characterization. Biochemistry 9, 298-303.

Valko, M., Rhodes, C. J., Moncol, J., Izakovic, M., and Mazur, M. (2006). Free radicals, metals and antioxidants in oxidative stress-induced cancer. Chem. Biol. Interact. 160, $1-40$.

Vítek, L., Jirsa, M., Brodanová, M., Kaláb, M., Mareček, Z., Danzig, V., Novotný, L., and Kotal, P. (2002). Gilbert syndrome and ischemic heart disease: a protective effect of elevated bilirubin levels. Atherosclerosis $160,449-456$.
Vitek, L., and Ostrow, J. D. (2009). Bilirubin chemistry and metabolism; harmful and protective aspects. Curr. Pharm. Des. 15, 2869-2883.

Wang, H. D., Yamaya, M., Okinaga, S., Jia, Y. X., Kamanaka, M., Takahashi, H., Guo, L. Y., Ohrui, T., and Sasaki, H. (2002). Bilirubin ameliorates bleomycin-induced pulmonary fibrosis in rats. Am. J. Respir. Crit. Care Med. 165, 406-411.

Wang, X., Chowdhury, J. R., and Chowdhury, N. R. (2006a). Bilirubin metabolism: applied physiology. Curr. Pediatr. 16, 70-74.

Wang, H., Lee, S. S., Dell'Agnello, C., Tchipashvili, V., d'Avila, J. C., Czismadia, E., Chin, B. Y., and Bach, F. H. (2006b). Bilirubin can induce tolerance to islet allografts. Endocrinology $147,762-768$.

Wegiel, B., Gallo, D., Csizmadia, E., Roger, T., Kaczmarek, E., Harris, C., Zuckerbraun, B. S., and Otterbein, L. E. (2011). Biliverdin inhibits Toll-like receptor-4 (TLR4) expression through nitric oxide-dependent nuclear translocation of biliverdin reductase. Proc. Natl. Acad. Sci. U.S.A. 108, 18849-18854.

Yamashita, K., McDaid, J., Ollinger, R., Tsui, T. Y., Berberat, P. O., Usheva, A., Csizmadia, E., Smith, R. N.,
Soares, M. P., and Bach, F. H. (2004). Biliverdin, a natural product of heme catabolism, induces tolerance to cardiac allografts. FASEB J. 18, 765-767.

Yoshida, T., and Kikuchi, G. (1974). Sequence of the reaction of heme catabolism catalyzed by the microsomal heme oxygenase system. FEBS Lett. 48, 256-261.

Yoshida, T., Noguchi, M., and Kikuchi, G. (1980). Oxygenated form of heme heme oxygenase complex and requirement for second electron to initiate heme degradation from the oxygenated complex. J. Biol. Chem. $255,4418-4420$

Yoshino, S., Hamasaki, S., Ishida, S. Kataoka, T., Yoshikawa, A., Oketani, N., Saihara, K., Okui, H., Shinsato, T. Ichiki, H., Kubozono, T., Kuwahata, S., Fujita, S., Kanda, D., Nakazaki, M. Miyata, M., and Tei, C. (2011). Relationship between bilirubin concentration, coronary endothelial function, and inflammatory stress in overweight patients. J. Atheroscler. Thromb. 18, 403-412.

Zhou, H., Qian, H., Liu, J., Zhu, D., Ding, W., Pan, P., Jin, D., Wang, J., and Li, W. (2011). Protection against lung graft injury from brain-dead donors with carbon monoxide, biliverdin, or both. J. Heart Lung Transplant. 30, 460-466.
Zhu, H., Wang, J., Jiang, H., Ma, Y., Pan, S., Reddy, S., and Sun, X. (2010). Bilirubin protects graftsagainst non-specific inflammationinduced injury in syngeneic intraportal islet transplantation. Exp. Mol. Med. 42, 739-748.

Conflict of Interest Statement: The author declares that the research was conducted in the absence of any commercial or financial relationships that could be construed as a potential conflict of interest.

Received: 15 January 2012; paperpending published: 10 February 2012; accepted: 21 February 2012; published online: 08 March 2012.

Citation: Ryter SW (2012) Bile pigments in pulmonary and vascular disease. Front. Pharmacol. 3:39. doi: 10.3389/fphar.2012.00039

This article was submitted to Frontiers in Drug Metabolism and Transport, a specialty of Frontiers in Pharmacology. Copyright (c) 2012 Ryter. This is an open-access article distributed under the terms of the Creative Commons Attribution Non Commercial License, which permits non-commercial use, distribution, and reproduction in other forums, provided the original authors and source are credited. 